\title{
Liebermanns Brodersen-Porträt
}

\author{
Marcus Köhler
}

$\mathrm{D}$ as vorgestellte, 1920 von Max Liebermann angefertigte Porträt Albert Brodersens (1857-1930) (Abb. 1) spielt im Oeuvre des Künstlers seltsamerweise nur eine nebensächliche Rolle, obwohl der Künstler und der damalige Berliner Stadtgartendirektor spätestens seit Dezember 1909 bei der Ausführung des o. g. Gartens zusammen arbeiteten. ${ }^{1}$ So schreibt Alfred Lichtwark an Liebermann:

»[...] ich gratuliere Ihnen, daß Sie in Brodersen einen Mann gefunden haben, dem es offenbar Spaß macht, Probleme zu wälzen und aus dem Zeichnen ins Bauen zu kommen. $\ll^{2}$

Und legt am 8. Februar 1910 bei der Konzeption der Heckengärten nach:

»Ich glaube, Herr Brodersen wird ganz ebenso fühlen und bin überzeugt, er würde bei der Bearbeitung auf dieselbe Lösung kommen. $\ll^{3}$

Spätestens seit seiner Berufung in die 1903 gegründete städtische Parkdeputation Berlin ist bei Liebermann eine aktive Beteiligung an gartenkünstlerischen Fragen festzustellen. In der Kommission, in die auch Stadtgartendirektor Hermann Mächtig (1837-1909) und Stadtbaurat Alfred Hoffmann (1852-1932) berufen wurden, ${ }^{4}$ sollte für Planungen von Grünanlagen eine Vorprüfung von Entwürfen stattfinden. So wurden beispielsweise 1903 die Vorschläge für den Rudolfplatz und den Arnswalder Platz behandelt. 1904 und 1905 fanden Sitzungen der Parkdeputation statt, bei denen die Ent- wicklung des Nordparks (seit $1905 »$ Schillerpark«) besprochen wurde. Dabei äußerte sich detailliert auch Liebermann, der eine stärkere Beteiligung der Künstler forderte. 5 Konsequenterweise war Liebermann 1908 auch Mitglied des Preisgerichts, das über die zukünftigen Planungen des Schillerparks entscheiden sollte. Zusammen mit Mächtig, dem Kölner Gartendirektor Fritz Encke (1861-1931) und dem Düsseldorfer Walter von Engelhardt (1864-1940), sowie Paul Schultze-Naumburg (1869-1949) und Lichtwark erhielt der Magdeburger Gartenarchitekt Friedrich Bauer (1872-1937) unter dem Titel »Freude schöner Götterfunken« schließlich den ersten Preis. ${ }^{6}$

Als Ende 1909 Liebermann, seine Tochter Käthe, Lichtwark und Brodersen den Landhausgarten planten, hatte gerade Brodersen als Nachfolger Mächtigs die Stelle des Gartendirektors der Stadt Berlin eingenommen; ${ }^{7}$ eine Position, die er bis 1926 innehaben sollte. Aufgrund dieser Ernennung gab er auch seine Firma Körner \& Brodersen in Steglitz auf, wobei er weiterhin Beratungen und Hilfestellung leistete. ${ }^{8}$ Diese - wie es hieß - »Privatpraxis « übernahm nach seinem Tod Ludwig Lesser. ${ }^{9}$

Obwohl Brodersen u. a. durch seine Ausbildung an der Gärtnerlehranstalt in Potsdam sich als Vertreter der Lenné-MeyerschenSchule sah, zeichnen seine Entwürfe und Vorschläge eine Nähe zur Reformgartenkunst auf. ${ }^{10}$ Er führte nicht nur viele Privatgärten aus (u. a. für die Familie von Siemens, Borsig und Hamspohns in Berlin, Schemel in Guben, Haus Lehrbach in Bergisch-Gladbach) sondern sorgte auch für die Aufstellung von Bebauungsplänen in Bergisch Gladbach 


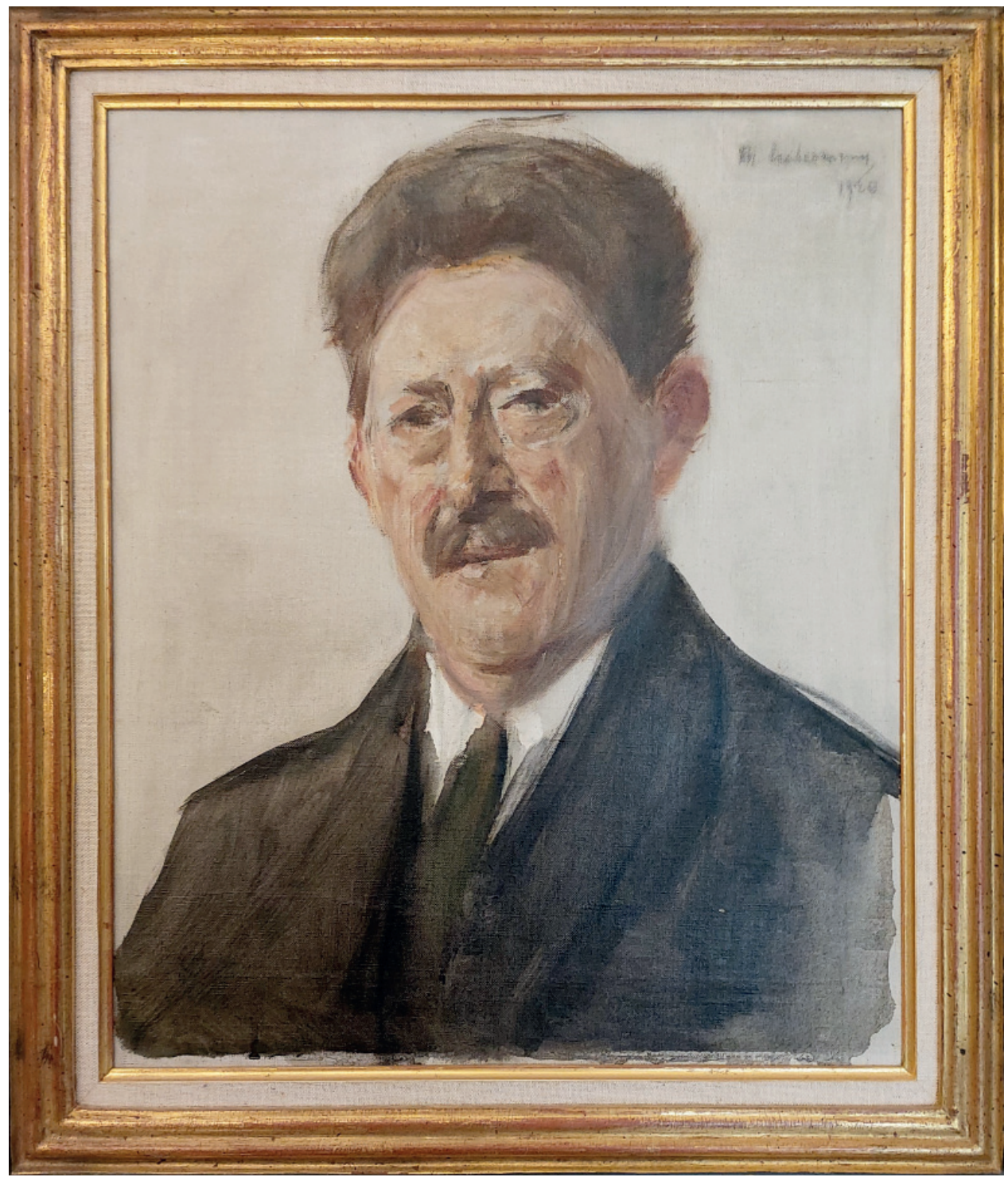

1 | Porträt von Albert Brodersen, Max Liebermann, Ölgemälde, 1920 (Privatbestand Stefan von Finckenstein). 
und Bernsberg und entwarf den Botanischen Garten in Berlin-Blankenfelde sowie Volksgärten (Erweiterung Berliner Viktoriapark und Kleistpark, Königspark Guben usw.), hinzu kam die Pferderennbahn im Grunewald und der Urnenfriedhof Wedding. Daneben arbeitete er häufig mit Architekten wie Alfred Messel (1853-1909), Emanuel (18561919) und Gabriel (1848-1913) von Seidl, dem Atelier Kayser von Carl Friedrich Ernst von Großheim (1841-1911) und Otto March (18451913) zusammen. ${ }^{11}$

Warum es zu dem Brodersen-Porträt kam, ist unbekannt. Es soll sich laut den Nachfahren um eine Ölskizze für ein größe-

1 Eberle, Matthias: Max Liebermann 1847-1935, Verzeichnis der Gemälde und Ölstudien, Bd. 2, München 1996, S. 1010 (Nr. 1920/16). Erstmals versteigert 1976 bei Ketterer, Köln, heute Privatbesitz.

2 Schellenbeg, Carl (Hg.): Alfred Lichtwark, Briefe an Max Liebermann, Hamburg 1947, S. 227, 4. Januar 1910.

3 Schellenberg, Lichtwarks Briefe, a. a. O., $237 f$.

4 Tagesgeschichte: Berlin (Parkdeputation), In: Die Gartenwelt 7.36 (1903), S. 432.

5 Verschiedene Mitteilungen: Professor Liebermann über Gartenkunst (Nordpark Berlin), In: Die Gartenkunst 6.5 (1904): 94; vgl. auch: Die Gartenkunst 7.11 (1905), S. 192.

6 Preisausschreiben: Schiller-Park (Berlin), In: Die Gartenwelt 12.14 (1908), S. 168; Wettbewerbe: Wettbewerb Schillerpark Berlin, In: Die Gartenkunst 10.6 (1908), S. 108. 1916 wurde Liebermann erneut wegen der Realisierung des Heldenhains im res Gemälde handeln, das im Zweiten Weltkrieg zerstört wurde. Tatsache ist, dass in jener Zeit im Atelier Liebermanns nicht nur viele intensive Gartengemälde entstanden, sondern auch äußerst lebendige Porträts, schreibt doch Gustav Pauli: »Der unermüdliche Liebermann malt ein Bildnis nach dem anderen. $\ll^{12}$ Obwohl es viele Auftragswerke darunter gab, muss man davon ausgehen, dass es sich hier um einen Freundschaftsdienst gehandelt hat. Ein bestelltes Werk hätte die Vermögensverhältnisse des in der Gustav-Meyer-Allee am Humboldthain wohnenden Brodersen sicherlich überstiegen.

Volkspark Wuhlheide gefragt, siehe: Chronik: Heldenhain Volkspark Wuhlheide (Berlin-Treptow), In: Der Städtebau 13.9 (1916), S. 94.

7 N. N.: A. Brodersen, In: Die Gartenkunst 12.2 (1910), S. 32.

8 Personalnachrichten DGfG, In: Die Gartenkunst 12.7 (Beil.) (1910): 8, s. a.: Nachfolger: Standesnachrichten, In: Die Gartenkunst 30.9 (Beil.) (1917), S. 3.

9 Siehe: Kurznachricht, In: Die Gartenwelt, 1930, 34 (7), S. 100.

10 N. N.: A. Brodersen, in: Die Gartenkunst 12.2 (1910), S. 32. $\mathrm{Zu}$ den Arbeiten siehe Hinweise In: Gartendenkmale in Berlin. Beiträge zur Denkmalpflege in Berlin, Bd. 27 (2008), Bd. 33 (2009)(2), Bd. 39 (2017).

11 Barth, Erwin: Unsere Toten, In: Die Gartenwelt 34.4 (1930), S. 56 (mit Porträt).

12 Gustav Pauli, 3.12. 1920 (Hamburger Kunsthalle, 119 A), nach: Eberle, S. 535 . 